\title{
Eco-geomorphology of banded vegetation patterns in arid and semi-arid regions
}

\author{
P. M. Saco ${ }^{1}$, G. R. Willgoose ${ }^{1}$, and G. R. Hancock ${ }^{2}$ \\ ${ }^{1}$ School of Engineering, The University of Newcastle, Callaghan, New South Wales, 2308, Australia \\ ${ }^{2}$ School of Environmental and Life Sciences, The University of Newcastle, Callaghan, New South Wales, 2308, Australia \\ Received: 13 June 2006 - Published in Hydrol. Earth Syst. Sci. Discuss.: 30 August 2006 \\ Revised: 25 September 2007 - Accepted: 25 September 2007 - Published: 1 November 2007
}

\begin{abstract}
The interaction between vegetation and hydrologic processes is particularly tight in water-limited environments where a positive-feedback links soil moisture and vegetation. The vegetation of these systems is commonly patterned, that is, arranged in a two phase mosaic composed of patches with high biomass cover interspersed within a lowcover or bare soil component. These patterns are strongly linked to the redistribution of runoff and resources from source areas (bare patches) to sink areas (vegetation patches) and play an important role in controlling erosion.

In this paper, the dynamics of these systems is investigated using a new modeling framework that couples landform and vegetation evolution, explicitly accounting for the dynamics of runon-runoff areas. The objective of this study is to analyze water-limited systems on hillslopes with mild slopes, in which overland flow occurs predominantly in only one direction and vegetation displays a banded pattern. Our simulations reproduce bands that can be either stationary or upstream migrating depending on the magnitude of the runoffinduced seed dispersal. We also found that stationary banded systems redistribute sediment so that a stepped microtopography is developed. The modelling results are the first to incorporate the effects of runoff redistribution and variable infiltration rates on the development of both the vegetation patterns and microtopography. The microtopography for stationary bands is characterized by bare soil on the lower gradient areas and vegetation on steeper gradients areas. For the case of migrating vegetation bands the model generates hillslope profiles with planar topography. The success at generating not only the observed patterns of vegetation, but also patterns of runoff and sediment redistribution suggests that the hydrologic and erosion mechanisms represented in the
\end{abstract}

Correspondence to: P. M. Saco

(patricia.saco@newcastle.edu.au) model are correctly capturing some of the key processes driving these ecosystems.

\section{Introduction}

Arid and semi-arid areas constitute over $30 \%$ of the world's land surface. These areas function as tightly coupled ecological-hydrological systems with strong feedbacks and interactions occurring across fine to coarse scales (Noy-Meir, 1973, 1981; Wilcox et al., 2003; Ludwig et al., 2005). Generally, the vegetation of these regions consists of a mosaic or pattern composed of patches with high biomass cover interspersed within a low-cover or bare soil component. A key condition for the development and maintenance of these patterns seems to be the emergence of a spatially variable infiltration field with low infiltration rates in the bare areas and high infiltration rates in the vegetated areas (Tongway and Ludwig, 2001). This spatially variable infiltration has been observed in many field studies and is responsible for the development of a runoff-runon system. Several field studies have reported much higher infiltration rates (up to 10 times) under perennial vegetation patches than in interpatch areas (Bhark and Small, 2003; Dunkerley, 2002; Ludwig et al., 2005). The enhanced infiltration rates under vegetated patches are due to improved soil aggregation and macroporosity related to biological activity (e.g., termites, ants, and earthworms are very active in semi-arid areas) and vegetation roots (Tongway et al., 1989; Ludwig et al., 2005). The amount of water received and infiltrated into the vegetation patches, which includes runon from bare areas, can be up to $200 \%$ the direct precipitation (Valentin et al., 1999; Wilcox et al, 2003; Dunkerley, 2002). The runoff-runon mechanism triggers a positive feedback, that is, increases soil moisture in

Published by Copernicus Publications on behalf of the European Geosciences Union. 


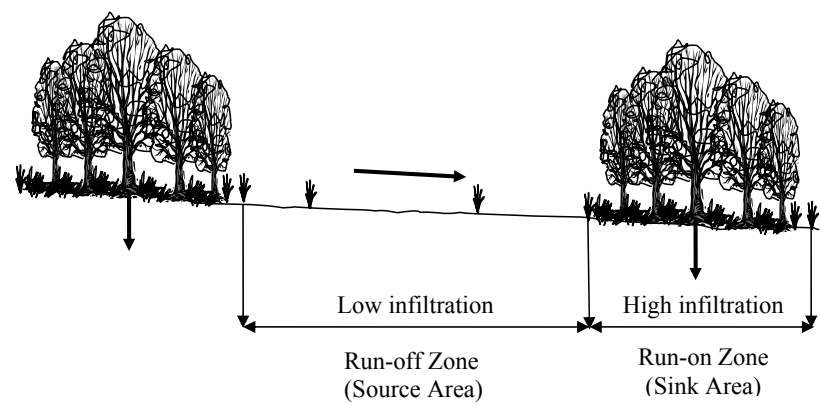

Fig. 1. Schematic diagram of the effect of banded vegetation patterns on flow redistribution.

vegetated patches reinforcing the pattern (Puigdefábregas et al., 1999; Valentin et al., 1999; Wilcox et al., 2003). The redistribution of water from bare patches (source areas) to vegetation patches (sink areas) is a fundamental process within drylands that may be altered if the vegetation patch structure is disturbed. This efficient redistribution of water is accompanied by sediments and nutrients and allows for higher net primary productivity.

The objective of this study is to investigate the interactions between dynamic vegetation patterns and geomorphology in banded vegetation systems, using a new coupled dynamic vegetation-landform evolution model. In particular, we are interested in analyzing if the simplified dynamics included in our model is able to reproduce not only the observed vegetation patterns but also the associated sediment redistribution that leads to stepped microtopography. In Sect. 2 we discuss the interactions between processes, patterns and function taking place in arid and semi-arid areas with sparse vegetation cover. We also describe some of the models used in previous studies. In Sect. 3 we describe the dynamic vegetation model used in this study. Section 4 provides a brief description of the SIBERIA landform evolution model (Willgoose et al., 1991). Section 5 explains how the models are coupled and the flow of information between the coupled models. Section 6 describes the simulation results for banded vegetation systems and final conclusions are summarized in Sect. 7.

\section{Ecohydrology of arid and semi-arid areas}

\subsection{Processes, patterns and function}

As discussed above, vegetation patterns play an important role on determining the location of runoff and sediment source and sink areas (Cammeraat and Imeson, 1999; Wilcox, 2003; Imeson and Prinsen, 2004). These patterns are thus functionally related to hydrologic processes through their effect on determining soil moisture patterns, runoff redistribution and evapotranspiration; and to geomorphologic processes through their role on determining the spatial distribution of erosion-deposition areas. In these systems the spa- tial redistribution of flows and material is regulated by both topography and vegetation (Tongway and Ludwig, 1997). That is, the downslope routing of water, sediments, nutrients, seeds, litter, etc, is strongly influenced by the interaction between vegetated and bare patches, which is determined by their spatial connectivity (Imeson and Prinsen, 2004). As shown by several field studies, natural vegetation patterns that take decades to hundreds of years to evolve provide stabilizing properties for ecosystems as they are efficient in reducing overland flow and land degradation, and help ecosystems to recover from disturbance and to resist stressors (Cammeraat and Imeson, 1999). Therefore the state of natural vegetation patterns constitutes an important indicator of ecosystem health.

Changes in the vegetation pattern and state in semi-arid regions are among the main indicators of the state of land degradation leading to desertification. If the vegetation cover is removed, the redistribution of water is altered inducing higher runoff rates and causing soil erosion during intense rainstorms. Disturbances, such as overgrazing, can alter the structure of vegetation patches reducing their density and/or size which leads to a "leaky" system. A leaky system is less efficient at trapping runoff and sediments and loses valuable water and nutrient resources (Ludwig et al., 2004) inducing a positive-feedback loop that reinforces the degradation process (Lavee et al., 1998). When semi-arid lands become degraded, their original biotic functions are damaged and the subsequent restoration of those lands is costly and in some cases impossible.

A common vegetation pattern found in arid and semi-arid ecosystems, usually referred to as spotted or stippled, consists of dense vegetation clusters that are irregular in shape and surrounded by bare soil (Lavee et al., 1998; Aguiar and Sala, 1999; Ludwig et al., 1999). Another common pattern is banded vegetation, also known as "tiger bush" in Africa and "mogotes" in Mexico, in which the dense biomass patches form bands, stripes or arcs (Aguiar and Sala, 1999; Ludwig et al., 1999; Valentin et al., 1999; d'Herbes et al., 2001). Banded vegetation is usually aligned along contour lines and is effective in limiting hillslope erosion (Bochet et al., 2000). The bands favor soil conservation by acting as natural bench structures in which a gently sloping runoff zone leads downslope onto an interception zone (Valentin et al., 1999). Figure 1 displays a schematic diagram of a banded system showing the redistribution of water from bare patches (source areas) to vegetation patches (sink areas). Banded patterns commonly act as closed hydrological systems (Valentin and d'Herbes, 1999), with little net outflow and sediment coming out of the system (e.g. at the bottom of the hillslope or catchment outlet). The effect of spotted vegetation on erosion is more complex and depends on the connectivity of the bare soil areas. Wilcox et al. (2003) reported the results from the interactions between runoff, erosion, and vegetation from an experimental study in an area with sparse vegetation cover (spotted vegetation) in New Mexico. They concluded that the 
redistribution of runoff and erosion occurs at the inter-patch scale (from bare patches to high biomass patches), with little or no effect at the hillslope scale. However, disturbances that modify vegetation can produce an increase in erosion rates leading to the creation of gullies and can result in irreversible degradation. That is, if vegetation establishes along the new drainage gullies the overland flow pattern is lost and it is unlikely that it will re-establish itself without human intervention (Wakelin-King, 1999).

Tongway and Ludwig (2001; and references therein) discuss some of the theories for the formation of banded landscapes. Some suggest that band formation is recent and due to the impact of humans in a previously uniform vegetation cover. Others suggest that is due to climatic shifts during the Holocene or to geomorphic processes that shaped the landscape. Water and wind are both considered band forming agents. However, in most cases water is perceived as the primary causal agent of band formation (Tongway and Ludwig, 2001). Although banded patterns have been found in landscapes with a wide range of steepness, from gentle to relatively steep slopes (Puigdefabregas and Sanchez, 1996; Bergkamp et al., 1999), the key condition for their appearance seems to be the ability of the landscape (soil and surface conditions) to generate surface runoff as sheet-flow (Valentin et al., 1999; Tongway and Ludwig, 2001). Landscapes with incised rills and gullies, in which flow concentration precludes the generation of sheet flow, do not exhibit banded vegetation. Moreover, studies in banded vegetation areas experiencing erosion and degradation have reported the disappearance of the banded system as soon as rills and channel incision begins (Tongway and Ludwig, 2001). In this paper we focus our analysis on banded systems driven by surface runoff (see d'Herbes et al., 2001, and references therein for a description of wind-driven banded systems). The coupled model described in this paper has been also used for a similar analysis on systems with stippled and spotted patterns and these results will be reported in a follow up paper (Saco and Willgoose, 2006, 2007 ${ }^{1}$ ).

\subsection{Previous models}

There is a variety of models for the simulation of vegetation pattern formation (e.g., Thiery et al., 1995; Lefever and Lejeune, 1997; Dunkerley, 1997; Klausmeier, 1999; Rietkerk et al., 2002; Gilad et al., 2004) and for the simulation of coupled hydrology and vegetation dynamics in water-limited ecosystems (e.g., Aguiar and Sala, 1999; Puigdefábregas et al., 1999; Porporato et al., 2003; Ludwig at al., 1999; Boer and Puigdefábregas, 2005). However, not all of them include the interactions between water redistribution and dynamic vegetation patterns. Recent models that capture the interaction between spatial water redistribution and vegetation pat-

\footnotetext{
${ }^{1}$ Saco, P. M. and Willgoose, G. R.: Eco-geomorphology and vegetation patterns in semi-arid regions: effect of slope and precipitation variability, in preparation, 2007.
}

terns can be divided in two main groups. The first group includes models developed to simulate water redistribution for a fixed spatial vegetation pattern (Puigdefábregas et al., 1999; Ludwig at al., 1999; Boer and Puigdefábregas, 2005). This type of models are used to understand the effect of vegetation patterns on erosion and/or water redistribution at short time scales (e.g., from storm event to annual timescales), but do not include feedback effects that occur at longer time scales. Significant changes in vegetation patterns can occur at time scales varying from several years to several decades (Gao and Reynolds, 2003; Brown et al., 1997) and thus these models can not be directly used to asses the impact of climate change or grazing pressure. The second group of models simulates the development and evolution of vegetation patterns as a function of water redistribution (Dunkerley, 1997; Klausmeier, 1999). In these models the pattern emerges from facilitation and competition feedbacks, such as increased infiltration under vegetation patches (HilleRisLambers et al., 2001; Rietkerk et al., 2002) or competition for the limiting water resource through the root system (Gilad et al., 2004). These models have provided valuable insight into the mechanisms responsible for the emergence and self-organization of the observed vegetation patterns in arid and semi-arid areas. However, they do not include the dynamic effect of erosiondeposition processes and their feedback effects on flow routing, soil moisture and vegetation pattern dynamics. That is, erosion-deposition mechanisms change topography affecting surface water redistribution and soil moisture patterns, which in turn affect the evolution of the vegetation pattern at longer time scales. These non-linear self-reinforcing effects may lead in some cases to the desertification of the system (Lavee et al., 1998). These types of feedback effects can be studied using a coupled dynamic vegetation-landform evolution model that incorporates evolving patterns of vegetation as the one described in this paper.

Recent research has incorporated the effect of dynamic vegetation on erosion and landform evolution for humid areas in which soil moisture does not limit vegetation growth (Collins et al., 2004; Istanbulluoglu and Bras, 2005). The results provide important insight into the effects of vegetation dynamics on geomorphic processes for humid areas. Unlike these previous studies the results presented here are for water limited environments, where plant growth depends on soil moisture availability which is assumed to be the most important limiting resource (i.e., plant growth is assumed not to be limited by nutrient availability).

\section{Dynamic vegetation model}

In this section we describe a new model for the development of vegetation patterns in water limited ecosystems. The dynamic vegetation model describes the dynamics of three state variables: plant biomass density ( $P$; mass/area), soil moisture $(M$; volume/area), and overland flow ( $Q$; discharge). 
The model is based on the one proposed by HilleRisLambers et al. (2001) and extended by Rietkerk et al. (2002). Unlike these previous models, our model incorporates surface water routing. The coupling of a surface water routing algorithm allows us to account for the effect of seed dispersal by overland flow (a possible mechanism for the emergence of stationary vegetation bands) and sediment redistribution not simulated by previous models.

\subsection{Overland flow dynamics}

The partial differential equations governing the redistribution of overland flow (run-on and run-off) are the conservation of mass and momentum. The full dynamic form of these equations for the description of free surface flow is known as the Saint Venant equations. A simplified version of the Saint Venant equations is the kinematic wave approximation, which includes a simplified momentum equation applicable to most practical hydrologic conditions where backwater effects are considered negligible (Vieux, 1991). The conservation of water mass (continuity) can be written as:

$$
\frac{\partial h(x, y, t)}{\partial t}=-\nabla \cdot \boldsymbol{q}(x, y, t)+R(x, y, t)-I(x, y, t)
$$

where $h[\mathrm{~m}]$ is the flow depth, $\boldsymbol{q}[\mathrm{mm} \mathrm{m} / \mathrm{day}]$ is the flow discharge per unit width, $R[\mathrm{~mm} /$ day $]$ is the rainfall rate, $I$ $[\mathrm{mm} /$ day $]$ is the infiltration rate, $x$ and $y[\mathrm{~m}]$ denote the position coordinates, $t$ [day] is time, $\nabla \cdot$ is the divergence operator, and the bold italic letters indicate vector quantities.

The conservation of momentum using the kinematic wave assumption is described as (Henderson and Wooding, 1964; Woolhiser and Liggett, 1967; Vieux, 1991; Mitas and Mitasova, 1998):

$S_{o}=S_{f}$

in which the friction slope $\left(S_{f}\right)$ is assumed to be the same as the land surface slope $\left(S_{o}\right)$. That is, kinematic wave theory assumes that shallow water waves are long and flat (Vieux, 1991). Closure to the above equations is given using Manning's equation to compute overland flow velocities (Julien et al., 1995; Eagleson, 1970; Mitas and Mitasova, 1998), so that the overland flow discharge per unit width can be expressed as:

$q(x, y, t)=\frac{c_{n}}{n} h(x, y, t)^{\frac{5}{3}} S_{o}(x, y, t)^{\frac{1}{2}}$

where $n$ is Manning's roughness coefficient and $\mathrm{c}_{n}$ the constant for unit conversion $\left(\mathrm{m} \mathrm{mm}^{-2 / 3} \mathrm{day}^{-1}\right)$. We use a spatially constant $n$ for simplicity, but changes in $n$ due to changes in local biomass can be included in the model (Istanbulluoglu and Bras, 2005).

A quasi steady approximation is adopted here and Eq. (1) is solved for steady state conditions $(\partial h / \partial t=0)$. This is justified since the time scale at which the rate of change of runoff redistribution occurs (seconds to hours) is much faster than that at which change of plant biomass occurs (days or longer for grasses to months for shrubs). Therefore, a time step of 0.5 day is used to model vegetation change and the amounts of $q$ and $h$ are represented by their equilibrium values which occur at much smaller time scales. The steady state approximation is also considered to provide an adequate estimate of overland flow for land management applications (Flanagan and Nearing, 1995; Mitas and Mitasova, 1998).

The magnitude and direction of overland flow and the slope $\left(S_{o}\right)$ can change with time in response to erosiondeposition processes. The direction of the flow discharge vector $\boldsymbol{q}$ and the surface slope $S_{o}$ are computed in the steepest descent direction and estimated (and updated) by the landform evolution model (more details are given in Sect. 5). For the cases analyzed in this paper the flow is one-dimensional, that is the direction of the flow lines (or stream tubes as defined by Vieux, 1991) coincide with the x-axis, and corresponds to the steepest descent direction without invoking any approximation. The spatial and temporal coordinates $(x, y, t)$ are not included in any of the equations that follow to simplify the notation.

Several analytical and experimental studies have related the spatial variability of infiltration rates to differences in both biomass density (Dunkerley, 2002; Bhark and Small, 2003; Ludwig et al., 2005) and flow depth along a hillslope (Dunne et al., 1991; Fox et al., 1997, 1998). The observations by Dunkerley (2002) on the spatial patterns of soil moisture and infiltration rates in a banded mulga woodland in arid central Australia provide evidence for the dependence of infiltration on biomass density for arid regions. He found that infiltration rates are highest close to tree stems and decline rapidly with increasing distance. In many studies in arid areas, vegetation has been observed to be located in elevated mounds of a few centimeters height (Dunkerley, 2000, and references therein; Dunkerley, 1997; Bochet et al., 2000; Eldridge and Rosentreter, 2004). Greater infiltration rates in these elevated mounds (due to the presence of roots, soil fauna, etc) would therefore induce an increase in the apparent infiltration rates, as flow depth increases and inundates these higher areas within the groves. A similar observation is reported by Dunne et al. (1991) who relates differences in soil macroporosity to differences in infiltration rates between the low-lying and the elevated (vegetated) parts of the microtopography. Investigations of this type show that infiltration rate is not solely determined by the soil matrix, but rather depends on a range of other factors including the dynamics of the flow crossing the surface and the extent to which the form and amplitude of the microtopography allows or precludes broad sheet flow or more concentrated thread flow. Experiments on crusted surfaces (Fox et al., 1998) also suggest that spatial variability in seal characteristics, which vary with microtopography, can also strongly influence infiltration rates for varying ponding depths. That is, an increase in ponding depth inundates areas of higher hydraulic conductivity producing a significant increase in the infiltration rate. 
Following the evidence provided in these previous field studies, we assume that the infiltration rate, $I$, depends on biomass density $P$ (Walker et al., 1981) and overland flow depth $h$ according to (HilleRisLambers et al., 2001; Rietkerk et al., 2002):

$I=\alpha h \frac{P+k_{2} W_{o}}{P+k_{2}}$

where $\alpha\left(\right.$ day $\left.^{-1}\right)$ defines the maximum infiltration rate, $k_{2}$ $\left(\mathrm{g} \mathrm{m}^{-2}\right)$ is the saturation constant of infiltration, and $W_{o}$ (dimensionless) is a process parameter that determines the dependence of the infiltration rate $I$ on biomass density $P$ $\left(0 \leq W_{o} \leq 1\right)$. For $W_{o}=1$ there is no biomass dependence while for $W_{o} \ll 1$ the infiltration rate increases significantly with increased biomass density. For any given value of flow depth $h$, the infiltration is lowest for bare soil conditions $\left(\alpha h W_{o}\right)$ and increases with increasing biomass density to asymptotically approach the maximum value $(\alpha h)$.

\subsection{Soil moisture dynamics}

The soil moisture $M(\mathrm{~mm})$ is defined as the plant available soil water (that is, the total soil moisture is $M_{t}=M+M_{\min }$, where $M_{\min }$ is the wilting point). Soil moisture changes are modeled using a simple single bucket approach, in which gains are due to infiltration and losses are due to plant water uptake, evaporation and deep drainage:

$\frac{\partial M}{\partial t}=I-g_{\max } \frac{M}{M+k_{1}} P-r_{w} M$

The second term represents soil water uptake by plants, which is assumed to be a saturating function of soil moisture availability (HilleRisLambers et al., 2001; Rietkerk et al., 2002). $g_{\max }\left[\mathrm{mm} \mathrm{g}^{-1} \mathrm{~m}^{2}\right.$ day $\left.^{-1}\right]$ is the maximum specific water uptake (asymptotic value of water uptake per unit of biomass density as $M$ increases) and $k_{1}(\mathrm{~mm})$ is the halfsaturation constant of specific water uptake. When $M=k_{1}$, water uptake (and growth rate, see Eq. 6) is at half its maximum rate. Therefore, the half-saturation constant describes the water uptake characteristics of different plant species, with low $k_{1}$ values indicating the ability of plants to thrive under water stress (low soil moisture) conditions. The third term represents soil moisture losses due to deep drainage. Losses are assumed to increase linearly with soil moisture availability, with $r_{w}\left[\right.$ day $^{-1}$ ] being the proportionality constant. Lateral soil moisture fluxes are assumed to be negligible in Eq. (5). Simulations including lateral soil moisture redistribution, through a simple diffusion term added to Eq. (5) (following Rietkerk et al., 2002), did not alter the patterns of vegetation, sediment re-distribution and microtopography shown in this paper.

\subsection{Vegetation dynamics}

The rate of change of plant biomass density $P\left(\mathrm{~g} \mathrm{~m}^{-2}\right)$ is determined by plant growth, senescence, and spatial dissem- ination of vegetation due to seed or vegetative propagation, and can be expressed as:

$\frac{\partial P}{\partial t}=c g_{\max } \frac{M}{M+k_{1}} P-d P+D_{p} \nabla^{2} P-\nabla \cdot \boldsymbol{q}_{s d}$

The first term represents plant growth, which is assumed to be directly proportional to water uptake (transpiration) with $c\left(\mathrm{~g} \mathrm{~mm}^{-1} \mathrm{~m}^{-2}\right)$ being the conversion parameter from water uptake to plant growth. Water uptake by roots is assumed to equal actual transpiration, without considering any variations in the water storage of vegetation. The maximum asymptotic plant growth is given by $c g_{\max }$ when soil moisture is not limiting. The main control of plant production is assumed to be water limitation, so when water supply through rain or runon is insufficient plant transpiration becomes less than potential and linearly decreases plant growth. Nutrient availability is assumed not to limit plant growth at this production level. The second term represents biomass density loss and $d\left(\right.$ day $\left.^{-1}\right)$ is the specific loss coefficient of biomass density due to mortality (disturbances such as vegetation removal by grazing can be included in this term through a higher coefficient $d$ ).

The last two terms in Eq. (6) account for plant dispersal. $D_{p}\left(\mathrm{~m}^{2} \mathrm{day}^{-1}\right)$ in the third term is the dispersal coefficient for isotropic processes such as wind and animal action (termites are important agents for seed dispersal in many arid and semi-arid areas) and $\nabla^{2}$ is the Laplacian operator. The fourth term accounts for plant propagation caused by the transport of seed biomass by overland flow. The seed biomass transport vector, $\boldsymbol{q}_{s d}\left(\mathrm{~g} \mathrm{~m}^{-1}\right.$ day $\left.^{-1}\right)$, has the direction of the overland flow and a magnitude, $q_{s d}$, given by:

$$
\begin{gathered}
q_{s d}=c_{1} q P \text { for } c_{1} q<c_{2} \\
q_{s d}=c_{2} P \text { for } c_{1} q>c_{2}
\end{gathered}
$$

where $c_{1}\left(\mathrm{~mm}^{-1}\right)$ and $c_{2}\left(\mathrm{~m} \mathrm{day}^{-1}\right)$ are process parameters. This mechanism for transport of seed biomass depends on the magnitude and direction of the overland flow discharge (i.e., transport limited conditions for seed redistribution), and its maximum value $\left(c_{2} P\right)$ depends on the total amount of seed biomass available for flow dispersal (i.e., production limited conditions) which is assumed to be proportional to the total biomass density $P$.

Previous models (HilleRisLambers et al., 2001; Rietkerk et al., 2002; Gilad et al., 2004) incorporated plant dispersal through seed or vegetative propagation by including a diffusion term (third term in Eq. 6) but they did not account for the transport of seeds by overland flow (fourth term). However, the redistribution of seeds by overland flow has been identified in field experiments as one possible explanation for the observed stationarity of vegetation bands (Dunkerley, 2002). As explained in more detail in Sect. 6.3, this model reproduces both stationary bands (as observed in Australia) and traveling vegetation bands (observed in Sudan and some other locations). 


\section{Landform evolution model}

SIBERIA is a physically based model of the evolution of landforms under the action of fluvial erosion, creep and mass movement. The elevations within the catchment are simulated by a mass-transport continuity equation applied over geologic time scales. Mass-transport processes considered include fluvial sediment transport, such as those modeled by the Einstein-Brown equation, and a conceptualization of diffusive mass movement mechanisms such as creep, rainsplash and landslide. The model averages these processes in time so that the elevations simulated are average elevations, indicative of the average of the full range of erosion events. The mathematical details of this model are discussed in Willgoose et al. (1991). The evolution of the landform at a point follows directly from the mass conservation of sediment:

$$
\frac{\partial z}{\partial t}=U-\left(\frac{\nabla \cdot \boldsymbol{q}_{s}}{\rho_{s}\left(1-n_{p}\right)}+\nabla \cdot \boldsymbol{q}_{d}\right)
$$

where $U\left(\mathrm{mday}^{-1}\right)$ is the rate of tectonic uplift, $\nabla$. is the divergence operator, $\boldsymbol{q}_{s}$ is the fluvial sediment transport per unit width $\left(\mathrm{T}_{\text {day }}{ }^{-1} \mathrm{~m}^{-1}\right), \boldsymbol{q}_{d}$ is the diffusive mass transport per unit width $\left(\mathrm{m}^{3} \mathrm{day}^{-1} \mathrm{~m}^{-1}\right), \rho_{s}$ is the density of the sediment, $n_{p}$ is the porosity of the sediment and the bold italics indicate vector quantities. Generically, Eq. (8) does not assume any particular sediment transport processes since it is simply a statement of sediment transport continuity. Rather it is our adopted process representation for $\boldsymbol{q}_{s}$ and $\boldsymbol{q}_{d}$ that determines the processes modeled.

Sediment transport by overland flow, under transport limited conditions, is modeled as:

$q_{s}=\beta_{1} q^{m_{1}} S^{n_{1}}$

where $q$ is the surface runoff per unit width (estimated in the vegetation model, see Sect. 3.1), $S$ is the slope in the steepest downslope direction, $m_{1}$ and $n_{1}$ are parameters in the fluvial transport model, and $\beta_{1}$ is the rate of sediment transport, function of sediment grain size and vegetation cover, analogous to the $K$ factor in other erosion models, e.g. CREAMS, USLE. Note that a transport limited model is needed in order to capture the effect of surface water redistribution on erosion/deposition processes. That is, the existence of spatially heterogeneous vegetation and spatially varying infiltration rates induces the appearance of areas of surface runoff that trigger erosion and areas of run-on that induce sediment deposition.

Biomass cover is one of the key factors influencing soil erodibility. This is due to the positive effect of the vegetation on improving soil quality through organic matter and litter contribution. Also, a more active fauna and flora, which is generated due to the combined effect of enhanced weathering, enhanced infiltration and a less contrasted microclimate, produces stronger aggregates (Zhang, 1994; Cerdà, 1998). Under semiarid and arid conditions, soil erodibility is highly dependent on the soil surface aggregation which is strongly influenced by vegetation. Field studies in semiarid areas show that the minimum soil aggregation is found in bare areas and increases with vegetation cover (Cerdà, 1998). Accordingly, we model the decrease in soil erodibility with increasing biomass density through the parameter $\beta_{1}$ that is assumed to linearly decrease as biomass density increases (similar to other linear formulations in the literature, e.g., Boer and Puigdefábregas, 2005) as:

$$
\begin{gathered}
\beta_{1}=\beta_{b}\left(1-\beta_{v} P\right) \text { for } \beta_{v} P<1-\frac{\beta_{\min }}{\beta_{b}} \\
\beta_{1}=\beta_{\min } \quad \text { for } \beta_{v} P \geq 1-\frac{\beta_{\min }}{\beta_{b}}
\end{gathered}
$$

That is, the erodibility parameter is maximum for bare soil $\left(\beta_{b}\right)$ and is assumed to decrease linearly with increasing biomass density at a rate given by $\beta_{v}$ to a minimum value given by $\beta_{\min }$.

Diffusive transport processes (e.g. rainsplash, soil creep) are modeled as:

$q_{d}=D S$

where $D\left(\mathrm{~m}^{3}\right.$ day $\left.^{-1} \mathrm{~m}^{-1}\right)$ is the diffusion coefficient, assumed here to be spatially constant. This diffusion model is widely used to conceptualize mass movement (Ahnert, 1976). Other forms of mass wasting like landslides and debris flows were not included in the analysis since they are not important in the mild-slope areas that are the main focus of this study. The direction of the vector $\boldsymbol{q}_{d}$ is assumed to be in the steepest downslope direction which is consistent with the assumption for overland flow estimated using Eq. (3) and involves no approximation for the cases presented in this paper.

\section{Coupled model}

The strategy for integrating the vegetation model and the landform evolution model has been to couple the models through the shared hydrologic (overland flow), ecologic (biomass density), and geomorphic (elevations and slopes) variables. The vegetation model and landform evolution model (SIBERIA) share the same computational grid but the processes simulated in each model operate over different time scales, and are therefore executed at different time steps. The time step in SIBERIA is based on the duration of erosive time scales (days to years), whereas the vegetation model that includes the computation of surface flow redistribution, soil moisture and vegetation dynamics utilizes shorter time steps (sub-daily). The models have not been tightly coupled to improve computational speed and performance. Figure 2 shows the flow of information between both models. The vegetation model computes the evolution and spatial distribution of biomass density and overland flow. These variables are input into the landform evolution model that computes sediment 


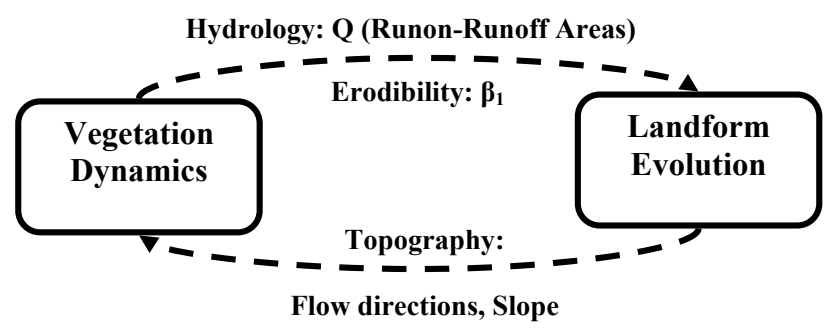

Fig. 2. Schematic diagram showing the flow of information between the coupled models.

transport. Biomass information is used to update the erodibility parameters which, together with overland flow distribution, are used to compute spatially distributed erosion and deposition volumes and to update elevations. The new topographic surface is then used to compute updated flow directions and slopes that are input to the next step of the vegetation model.

\section{Results and discussion}

\subsection{Methodology}

The simulations analyzed in this section correspond to a two-dimensional hillslope with an area of $200 \mathrm{~m} \times 200 \mathrm{~m}$ and a grid spacing of $2 \mathrm{~m}$. No-flow boundary conditions were set for the upstream and lateral borders, while free flow boundary conditions were used in the downstream boundary (drainage was allowed through the complete downhill border of the domain). The initial hillslope profile corresponds to a planar slope of $1.4 \%$ that is typical of areas with banded vegetation in Australia (Dunkerley and Brown, 1999). The initial vegetation consisted of biomass peaks randomly distributed in $1 \%$ of the grid elements. The rest of the grid elements were set to bare soil conditions. The precipitation for the simulations shown in this paper was set to $320 \mathrm{~mm} /$ year (high values of precipitation lead to continuous biomass cover as discussed in Rietkerk et al., 2002).

The parameters for vegetation dynamics used in this analysis (shown in Table 1) were adopted following those reported by Rietkerk et al. (2002) and HilleRisLambers et al. (2001) for the analysis of vegetation patterns in grasslands. The surface roughness coefficient (i.e., Manning's coefficient) corresponds to commonly accepted values in vegetated surfaces. These parameters give rise to low biomass vegetation that evolves into equilibrium conditions rapidly (fast dynamics). Different sets of parameters can be selected to simulate growth and development of vegetation dynamics similar to that of shrubs and grasses for semi-arid areas reported in previous studies (Sparrow et al., 1997; Gao and Reynolds, 2003; Saco and Willgoose, 2006). Table 2 shows the parameters for the erosion processes included in the landform evolution model used in all simulations, chosen from the range of re-
Table 1. Parameters used in the vegetation model.

\begin{tabular}{ccc}
\hline$n$ & - & 0.05 \\
$\alpha$ & day $^{-1}$ & 28 \\
$k_{2}$ & $\mathrm{~g} \mathrm{~m}^{2}$ & 18.0 \\
$W_{o}$ & - & 0.05 \\
$g_{\max }$ & $\mathrm{mm} \mathrm{g}^{-1} \mathrm{~m}^{2} \mathrm{day}^{-1}$ & 0.05 \\
$k_{1}$ & $\mathrm{~mm}^{-1}$ & 5.0 \\
$r_{w}$ & day $^{-1}$ & 0.19 \\
$c$ & $\mathrm{~g} \mathrm{~mm}^{-1} \mathrm{~m}^{-2}$ & 10.0 \\
$d$ & day $^{-1}$ & 0.24 \\
$D_{p}$ & $\mathrm{~m}^{2}$ day $^{-1}$ & 0.3 \\
$c_{1}$ & $\mathrm{~mm}^{-1}$ & 2.25 \\
$c_{2}$ & $\mathrm{~m} \mathrm{day}^{-1}$ & 0.2 \\
\hline
\end{tabular}

Table 2. Parameters used in the landform evolution model.

\begin{tabular}{cc}
\hline Grid size $\left(\mathrm{m}^{2}\right)$ & 2 \\
$\mathrm{U}\left(\mathrm{m} \mathrm{y}^{-1}\right)$ & 0.0 \\
$\mathrm{D}\left(\mathrm{m}^{3} \mathrm{~s}^{-1} \mathrm{~m}^{-1}\right)$ & $0.0-0.05$ \\
$m_{1}$ & 1.8 \\
$n_{1}$ & 1.1 \\
$\beta_{b}$ & 0.05 \\
$\beta_{v}$ & 0.05 \\
$\beta_{\min }$ & 0.0 \\
\hline
\end{tabular}

commended values (Willgoose, 2004). As seen in Table 2, the simulations shown in this paper correspond to the case of declining equilibrium conditions $(U=0)$.

\subsection{Self organization into banded vegetation patterns}

The initial distribution of biomass density is shown in Fig. 3a. On a hillslope in which overland flow occurs predominantly in only one direction (as sheet flow with no flow concentration) the coupled model generates regular vegetation bands perpendicular to the flow direction (tiger bush or banded type of pattern). For the parameters shown in Tables 1 and 2, stationary vegetation bands have completely developed for $t>15$ years. Figures $3 \mathrm{~b}$ and $\mathrm{c}$ show two stages in band development for $t=2560$ days and $t=15$ years respectively.

The evolution of vegetation bands results from the system functioning as a series of runoff-runon areas that arise due to facilitation (of infiltration) and competition (for soil moisture) by plants. Runoff is produced in the bare areas and increases downslope towards the upper boundary of the vegetated patches (groves). Vegetation colonizes (by growth and dispersion) areas with sufficient soil moisture, which receive runoff water from upslope. Infiltration is high within the vegetation patches (areas with high biomass density), which act 


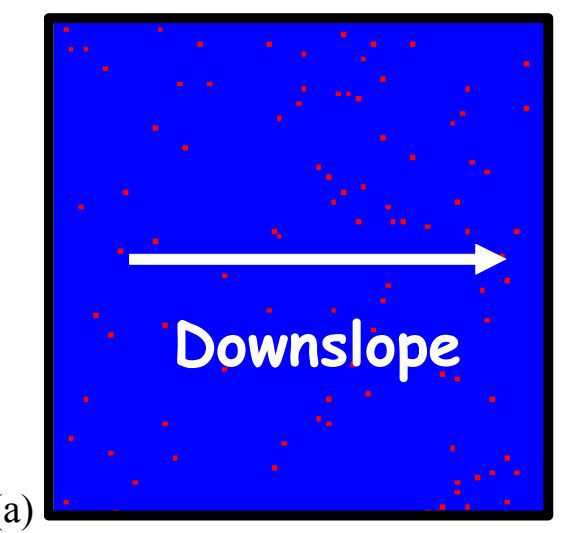

(b)

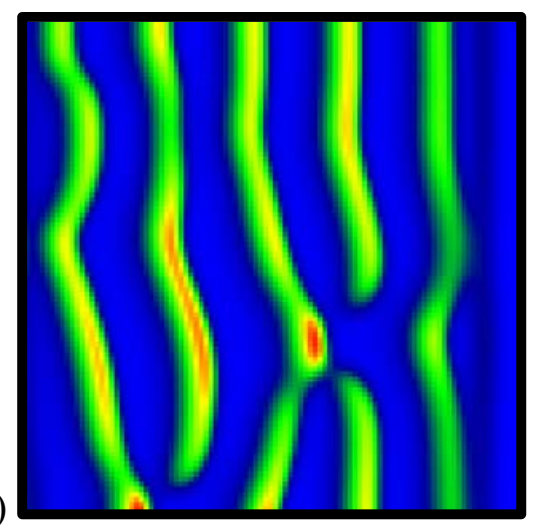

(c)

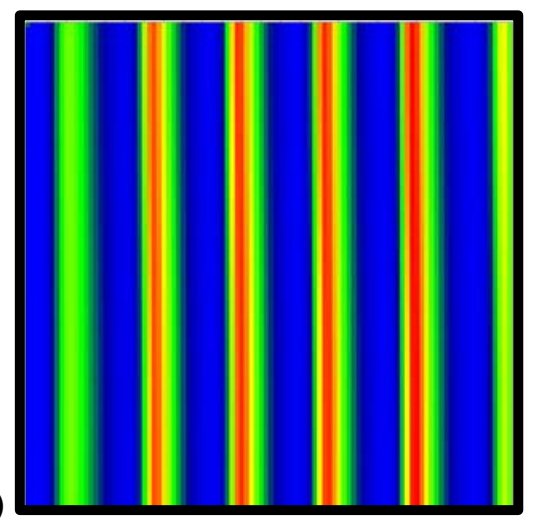

Fig. 3. Self-organization of vegetation into a banded pattern for a planar hillslope with sheet flow. The scale is $200 \mathrm{~m} \times 200 \mathrm{~m}$ on a slope of $1.4 \%$. (a) Initial conditions of random plant peaks in $1 \%$ of the grid elements, (b) Vegetation pattern for $t=2560$ days, (c) Stationary bands have completely developed for $t=15$ years.

as sinks for the water coming from upslope (runon areas) and restrict the runon that is passed on to the vegetated areas situated further downslope. After a distance set by runon availability, soil moisture becomes inadequate for plant growth

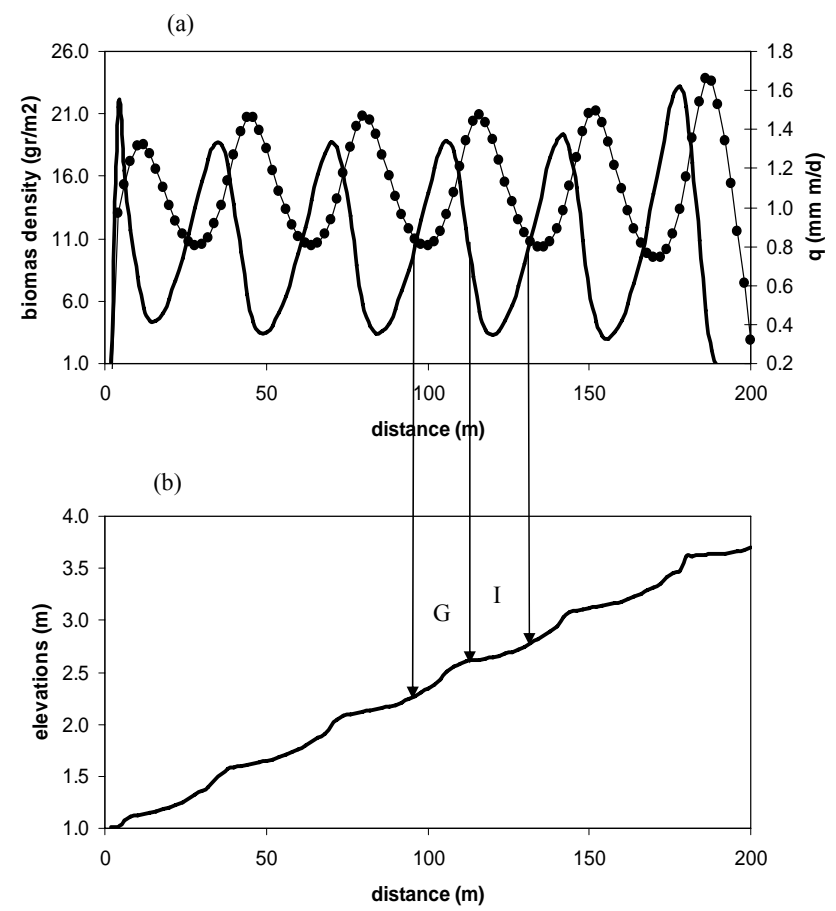

Fig. 4. Longitudinal profile of a banded vegetation pattern, the $x$ axis shows distance from the bottom of the hillslope, (a) simulated distribution of biomass density (solid line) and runoff (dots), (b) simulated elevations after 500 years. The vertical arrows show the position of a grove (G) and an intergrove (I).

requirements, and biomass decreases giving way to an area with very low biomass density (intergrove). The intergrove has low infiltration rates allowing for a progressive increase in runoff volume downslope from the grove boundary. When sufficient runoff becomes available to satisfy soil moisture requirements for biomass growth, another patch of vegetation emerges (grove).

The bands grow laterally (through seed dispersal) because plants located at the same distance from the upstream vegetation boundary receive the same amount of water. Therefore, the vegetated patches expand laterally allowing for the formation of parallel bands typical of banded systems. Note that this is the case because surface flow is in the form of sheet flow, with no flow concentration, and flowlines are parallel (perpendicular to the groves). For simplicity, lateral competition for water via the root system has not been included in the model.

Figure 4a displays the distribution of biomass along the longitudinal profile. The biomass cover is continuous, but its spatial distribution displays high densities (groves) and low densities (intergroves) in a periodic pattern. Figure 4a also shows the overland flow for the stationary vegetation bands, showing that the spatial variability of runoff and that of biomass density are out of phase. That is, runoff is higher in the areas with the minimum biomass density (low 
infiltration) and lower in the areas with higher biomass (high infiltration).

\subsection{Stationary and migrating bands}

As mentioned in Sect. 3, the appearance of stationary bands is due to the effect of anisotropic seed dispersal resulting from the preferential redistribution of seeds by surface flow downslope. This mechanism was not included in previous models which only reproduced vegetation bands moving uphill (Klausmeier, 1999; HilleRisLambers et al., 2001; Rietkerk et al., 2002; Gilad et al., 2004). The migration of vegetation bands in the uphill direction remains a controversial topic, with field studies reporting evidence that supports both the existence of migrating bands and stationary bands in different landscapes (Valentin et al., 1999; Ludwig and Tongway, 2001). As discussed by Valentin et al. (1999), evidence of upslope migration remains scarce. The direct observations of band movement over short time spans do not give compelling information due to the slow velocity of the migrating bands. In particular, several field studies in Australia have reported the existence of stationary bands and one of the possible reported mechanisms that might prevent the bands from traveling upstream is seed redistribution by overland flow. Observations by Dunkerley and Brown (2002) for a 6year period on a banded chenopod shrubland in Western New South Wales in Australia show no evidence of systematic migration of grove-intergrove boundaries. They found that the majority of the bands remained in place within the limits of measurement accuracy (typically, $0.5 \mathrm{~m}$ ). Similarly, Dunkerley (2002) found no evidence of systematic upslope pattern migration over a 24-year study period on a banded pattern of Mulga trees near Alice Springs in Australia. Accordingly, Dunkerley and Brown (2002) and Dunkerley (2002) concluded that these results provided field evidence in contradiction with existing numerical models based on "runoff-runon" mechanisms for pattern generation that predict upslope migration of patterns (for example, Klausmeier, 1999; Rietkerk et al., 2002; among others). However, as shown here, our model based on runoff-runon mechanisms reproduces both stationary and migrating bands.

As explained in Sect. 3.3, the parameters $c_{1}$ and $c_{2}$ control the dynamics of seed transport by overland flow. Consequently these parameters are the ones that control the appearance of either stationary or migrating banded vegetation patterns. The amount of seeds transported by overland flow depends on the transport capacity of the flow (i.e., transport limited conditions for seed redistribution by overland flow) but is constrained by the amount of seeds available for dispersal at any point of the landcape (i.e., production limited conditions), which is assumed to be proportional to the total biomass density $\left(c_{2} P\right)$. We analyzed the results from the model for increasing values of the parameter $c_{2}$ (we used $c_{1}=2.25 \mathrm{~mm}^{-1}$ to ensure that seed dispersal does not occur under transport limited conditions). When $c_{2}=0 \mathrm{~m} /$ day, there is no redistribution of seeds by overland flow, and the simulations result in the appearance of migrating bands. When $c_{2}$ is small $\left(c_{2}<0.1 \mathrm{~m} /\right.$ day $)$, the amount of seed dispersal by overland flow is lower than the seed dispersal by isotropic mechanisms, there is a preferential colonization of the upstream boundary (due to higher soil moisture conditions in these areas) and the bands migrate upstream. For higher values of $c_{2}\left(0.1 \mathrm{~m} /\right.$ day $<c_{2}<0.8 \mathrm{~m} /$ day $)$, there is no preferential growth of the band in the uphill direction and the bands become stationary. An example of a stationary banded pattern is shown in Fig. 4, in which $c_{2}=0.2 \mathrm{~m} /$ day. Finally, we found that for larger values of $c_{2}\left(c_{2}>0.8 \mathrm{~m} /\right.$ day $)$ the bands disappear and the complete hillslope has bare soil conditions. This occurs because the dispersal of seeds by overland flow becomes dominant. That is, the bands of vegetation move downhill due to enhanced preferential colonization of the downslope portions of the grove and, as there is no source of seeds in the most uphill portion of the landscape, the vegetation pattern slowly disappears from the hillslope. Though this is an interesting result, it does not lead to the banded landscapes that are the focus of this paper.

For the case of migrating bands, the dynamic patterns reproduced in our simulations are slightly different from those reported previously (e.g., in Rietkerk et al., 2002). This is mainly due to the difference in boundary conditions used in our analysis. As we are interested in the interactions between vegetation pattern, flow redistribution and erosion-deposition in hillslopes, we imposed a no-flow boundary condition in the upstream boundary (instead of the periodic boundary used in previous work). Therefore, for the case of migrating bands, the most upstream band decreases in size as it approaches the hilltop and finally dies out when the contributing area (and flow) becomes insufficient to maintain vegetation growth.

\subsection{Geomorphology-ecohydrology interactions}

Figure $4 \mathrm{~b}$ shows the simulated hillslope profile (elevations) for $t=500$ years. As seen in this figure, the initially planar hillslope evolves into a profile with stepped microtopography. This is a "declining relief" profile which undergoes a continuing loss of elevation with time, and in which the stepped microtopography becomes more pronounced with time. This type of hillslope profile is in agreement with the field data obtained by Dunkerley and Brown $(1995,1999)$ in both banded mixed shrubland-grassland and chenopod shrubland communities in Australia. Figure 5 shows the hillslope topography for one of their study sites. As observed in this figure the hillslope surface profile is composed of a series of concave-upward elements (Dunkerley and Brown, 1999). Figure 6a shows a schematic representation of the stepped microtopography generated by the model. Figure $6 \mathrm{~b}$ shows the schematic representation of the stepped microtopography reported by Dunkerley and Brown (1999). These figures show good agreement; the series of microtopographic 


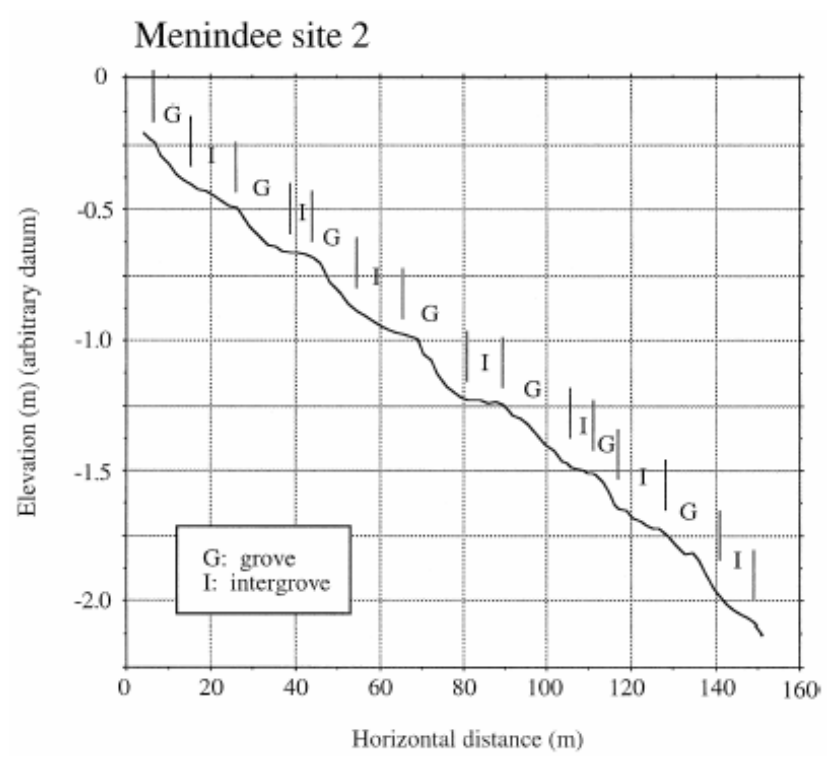

Fig. 5. Topographic profile of a site with banded vegetation, "G" indicates the groves or vegetated areas and "I" indicates the intergroves or bare soil areas (from Dunkerley and Brown, 1999). Reprinted from Catena, vol. 37, Dunkerley, D. L. and Brown, K. J.: Banded vegetation near Broken Hill, Australia: significance of surface roughness and soil physical properties, pages 75-88, 1999, with permission from Elsevier.

elements represented in both figures have similar shape and have the runon zone located upslope and the runoff zone below. What is particularly interesting about the simulated hillslope profile shown in Fig. 4 and represented in Fig. 6a is that most of the vegetated bands (groves) are located in the regions of higher slope, and not on the flatter areas as could have been expected from differences in erodibility between bare and vegetated areas.

The concave-upward element in Figs. 6a and b, composed of an upper grove and the lower intergrove, exhibits a smooth decline in gradient and displays no break of slope. Figure $6 \mathrm{~b}$ includes a slight depositional ridge which is not reproduced in our model (Fig. 6a) but that was only observed in some of the field sites studied by Dunkerley and Brown (e.g., there are no evident depositional ridges in the transect shown in Fig. 5). Each concave-upward element functions as a sourcesink unit. In the intergrove areas, increasing amounts of sediments are removed by runoff that increases with distance from the upper grove boundary. At the boundary of the grove where runoff is highest, the depth of flow is also highest inducing high infiltration rates (see Eq. 4). Therefore, these areas become important sinks of water (runon) and sediments with the highest simulated depositional rates. This result is in agreement with observations reporting that both ponding of water and sediment deposition are highest in the upslope margin of the groves (Dunkerley and Brown, 1999). The simulated runon decreases downslope from the grove upper boundary, therefore the amount of sediments deposited also decreases. The simulated erosion-depositional functioning of the pattern successfully reproduces observations.

Elsewhere in Australia, similar microtopography has been observed in banded vegetation areas. Topographic profiles of patterned Mulga in central Australia (Berg and Dunkerley, 2004) display stepped microtopography with intergroves located on lower gradients concave-upward areas and groves found on steeper gradients and straighter (not concaveupward) areas. This same type of microtopography has been observed in another site of patterned Mulga in central Australia (Slatyer, 1961) and in Western Australia (Mabbutt and Fanning, 1987). However the stepped microtopography of patterned Mulga lands in eastern Australia (south-western Queensland and northwestern New South Wales) is different. Mulga groves occur on nearly level "steps" in the landscape and there is a gradual drop into the grove and a more distinct "scarp" below the grove (Tongway and Ludwig, 1990).

Several researchers have observed and analyzed the appearance of the stepped microtopography on patterned landscapes and have linked it to spatial differences in soil erosion rates (Tongway and Ludwig, 1990; Sánchez and Puigdefábregas, 1994; Puigdefábregas and Sánchez, 1996) and redistribution of soil in runon areas (Dunkerley, 2002). In particular, Sánchez and Puigdefábregas (1994) and Puigdefábregas and Sánchez (1996) modeled the development of tussock vegetation and the mounds that form due to differential erosion rates induced by the vegetation. However, the modeling results presented here are the first to include the effect of runoff redistribution, through variable infiltration rates, on the development of both the vegetation patterns and the stepped microtopography. An extended sensitivity analysis of the erosion and runoff redistribution parameters is still needed to see if the differences in microtopography observed in different landscapes (described in the previous paragraph) can be explained by differences in process parameters.

It is important to note here that the stepped microtopography arises in our model in response to the presence of erosional and depositional areas prescribed by the location of the vegetation bands that are stationary. In contrast, we found that the profile does not evolve into stepped microtopography when migrating bands are reproduced (for example for $c_{2}=0$ in Eq. 7), because the erosion and depositional areas migrate with the bands.

\section{Summary and conclusions}

A coupled dynamic vegetation-landform evolution model for water limited ecosystems has been developed. This model was used to explore the interactions between patterned vegetation and erosion by explicitly accounting for the effect of dynamic water redistribution not considered in previous models (Ludwig et al., 1999; Puigdefábregas et al., 1999). 
(a)

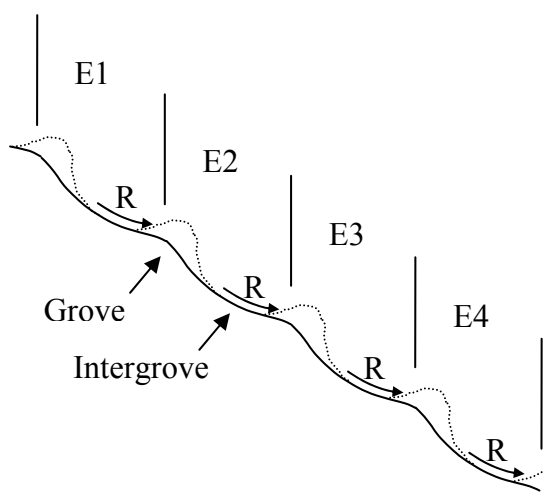

(b)

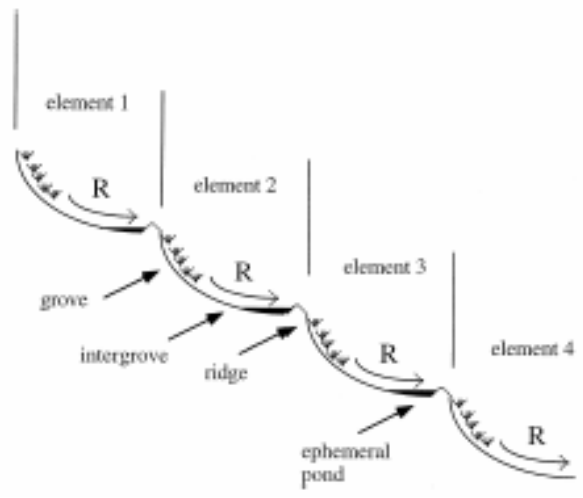

Fig. 6. (a) Schematic diagram of the microtopographic profile (continuous line), vegetation (dashed line) and surface water redistribution (curved arrows) that arises (self-organizing) from our model. (b) Schematic diagram of the microtopographic framework reported by Dunkerley and Brown [1999] for the description of banded vegetation characteristics. Panel (b) reprinted from Catena, vol. 37, Dunkerley, D. L. and Brown, K. J.: Banded vegetation near Broken Hill, Australia: significance of surface roughness and soil physical properties, pages 75-88, 1999, with permission from Elsevier.

That is, previous models did not account for the dynamic effect of erosion-deposition processes and their feedback effects on flow routing, soil moisture and vegetation pattern dynamics. The erosion-deposition mechanisms change topography affecting surface water redistribution and soil moisture patterns.

The analysis in this paper focussed on hillslopes with mild slopes. Under such conditions overland flow occurs predominantly in only one direction (as sheet flow with no flow concentration) and vegetation self organizes into a banded pattern. We used the coupled model to investigate and understand the dynamics of these systems. Some key results are summarized in what follows:

- We simulated and analysed the dynamics of both stationary and migrating vegetation bands (depending on the choice of model parameters). In both cases the bands self organize perpendicular to the flow direction (tiger bush or banded type of pattern) and their appearance is associated with the emergence of a runon-runoff pattern. We found that the effect of anisotropic seed dispersal due to the preferential redistribution of seeds by surface flow downslope can be responsible for the appearance of stationary bands. That is, seeds carried downstream by overland flow compensate for the tendency of bands to colonize upstream soil moisture rich areas, which would occur as a result of isotropic seed dispersal mechanisms. In this way, our model reproduces stationary bands when the parameters are set to represent conditions of significant transport of seeds by overland flow, or migrating bands when this transport mechanism is negligible. Previous models did not include this effect and, unlike the model presented here, only captured the dynamics of migrating bands (Klaus- meier, 1999; HilleRisLambers et al., 2001; Rietkerk et al., 2002; Gilad et al., 2004).

- We studied and characterized the dynamics of sediment redistribution that gives rise to hillslope profiles with a stepped microtopography for the case of stationary vegetation bands. The modelling results are the first to incorporate the effects of runoff redistribution and variable infiltration rates on the development of both the vegetation patterns and the associated microtopography. We found that the intergroves tend to be located on lower gradient areas that are concave-upward, and the groves are situated on steeper gradient (not concaveupward) areas. Sediments are removed from the upper intergrove areas by the effect of increasing runoff and deposited in the grove areas due to a decrease in runoff as a result of higher infiltration rates (Fig. 4). The simulated erosion-depositional functioning of the pattern successfully reproduces observations (Dunkerley and Brown 1995, 1999).

- For the case of migrating vegetation bands, we found that the erosion and depositional areas continuously move with the bands. In this case, the model generates hillslope profiles with planar topography.

The success at generating not only the observed patterns of vegetation, but also patterns of runoff and sediment redistribution (which originates the observed microtopography) suggests that the hydrologic and erosion mechanisms represented in the model are correctly capturing some of the key processes driving these ecosystems. Understanding the nonlinear interactions between vegetation patterns, runoff processes and erosion in arid and semi-arid areas becomes of crucial importance due to current accelerated changes in land 
use and climate. This simple model can be used to study feedback effects between geomorphology and vegetation under land use or climate change. Further research is needed to study the sensitivity of model to additional non-linear effects not included here. One example is the possible hysteresis effects arising from vegetation impacts on soil properties. For certain vegetation-soil systems, the positive effect of vegetation on infiltration and other soil properties may remain for considerable time after the vegetation cover has declined. Including this hysteresis effect could have important implications for the resulting pattern of vegetation, erosion rates and consequently could help us explain differences in observed microtopography/vegetation for different regions.

The analysis presented in this paper focuses on the interaction between vegetation patterns, flow dynamics and sediment redistribution for areas with mild slopes where sheet flow occurs and banded vegetation patterns emerge. The extent of the appearance of this type of pattern is widespread throughout the mild-slope arid and semi-arid areas of the world (see Fig. 3 in Valentin et al., 1999, for a map showing the global distribution of banded patterns). When flow concentration occurs, for example by incorporating an initially irregular slope (or some noise to the initial surface) the model generates different vegetation patterns (spots and stripes aligned to the direction of flow) and the redistribution of flow and sediments is remarkably different from the results reported here for banded vegetation. These results will be reported elsewhere (Saco and Willgoose, 2006, 2007¹).

Acknowledgements. This work was supported by a postdoctoral fellowship from The University of Newcastle and a grant from the Australian Research Council (DP0774184). We would like to thank the reviewers for providing comments and suggestions to improve the manuscript.

Edited by: C. Hinz

\section{References}

Ahnert, F.: The role of the equilibrium concept in the interpretation of landforms of fluvial erosion and deposition, in: L'evolution des versants, edited by: Macar, P., p. 23-41, University of Liege, Liege, 1967.

Aguiar, M. R. and Sala, O. E.: Patch structure, dynamics and implications for the functioning of arid ecosystems, Trends in Ecology and Evolution, 14, 273-277, 1999.

Berg, S. S. and Dunkerley, D. L.: Patterned Mulga near Alice Springs, central Australia, and the potential threat of firewood collection on this vegetation community, J. Arid Environ., 59, 313-350, 2004.

Bergkamp, G., Cerda, A., and Imeson, A. C.: Magnitude-frequency analysis of water redistribution along a climate gradient in Spain, Catena, 37, 129-146, 1999.

Bhark, E. W. and Small, E. E.: Association between plant canopies and the spatial patterns of infiltration in shrubland and grassland of the Chihuahuan Desert, New Mexico, Ecosystems, 6, 185196, 2003.
Bochet, E., Poesen, J., and Rubio, J. L.: Mound development as an interaction of individual plants with soil, water erosion and sedimentation processes on slopes, Earth Surf. Proc. Land., 25, 847-867, 2000.

Boer, M. and Puigdefábregas, J.: Effects of spatially structured vegetation patterns on hillslope erosion in a semiarid Mediterranean environment: a simulation study, Effects of vegetation patterns on erosion, Earth Surf. Processes Landforms, 30, 149-167, 2005.

Brown, J. H., Valone, T. J., and Curtin, C. G.: Reorganization of an arid ecosystem in response to recent climate change, Proceedings of the National Academy of Sciences (USA), 94, 9729-9733, 1997.

Cammeraat, L. H. and Imeson, A. C.: The evolution and significance of soil-vegetation patterns following land abandonment and fire in Spain, Catena, 37(1-2), 107-127, 1999.

Cerdà, A.: Soil aggregate stability under different Mediterranean vegetation types, Catena, 32, 73-86, 1998.

Collins, D. B. G., Bras, R. L., and Tucker, G. E.: Modeling the effects of vegetation-erosion coupling on landscape evolution, J. Geophys. Res., 109, F03004, doi:10.1029/2003JF000028, 2004.

d'Herbes, J. M, Valentin, C., Tongway, D., and Leprun, J. C.: Banded Vegetation Patterns and related Structures, in: Banded vegetation patterning in arid and semiarid environments: ecological processes and consequences for management, Ecological studies 149, Springer-Verlag, New York, USA, 1-19, 2001.

Dunkerley, D. L.: Banded vegetation: development under uniform rainfall from a simple cellular automation model, Plant Ecology, 129, 103-111, 1997.

Dunkerley, D. L.: Assessing the influence of shrubs and their interspaces on enhancing infiltration in an arid Australian shrubland, Rangeland Journal, 22(1), 58-71, 2000.

Dunkerley, D. L.: Infiltration rates and soil moisture in a groved Mulga community near Alice Springs, arid central Australia: evidence for complex internal rainwater redistribution in a runoffrunon landscape, J. Arid Environ., 51, 199-219, 2002.

Dunkerley, D. L. and Brown, K. J.: Runoff and runon areas in a patterned chenopod shrubland, arid western New South Wales, Australia: characteristics and origin, J. Arid Environ., 30, 41-55, 1995.

Dunkerley, D. L. and Brown, K. J.: Banded vegetation near Broken Hill, Australia: significance of surface roughness and soil physical properties, Catena, 37, 75-88, 1999.

Dunkerley, D. L. and Brown, K. J.: Oblique vegetation banding in the Australian arid zone: implications for theories of pattern evolution and maintenance, J. Arid Environ., 51, 163-181, 2002.

Dunne, T., Zhang, W., and Aubry, B. F.: Effects of rainfall, vegetation, and microtopography on infiltration and runoff, Water Resou. Res., 9, 2271-2285, 1991.

Eagleson, P. S.: Dynamic Hydrology, McGraw-Hill Book Company, New York, 351 p., 1970.

Eldridge, D. J. and Rosentreter, R. R.: Shrub mounds enhance water flow in a shrub-steppe community in southwestern Idaho, USA, in: Seed and soil dynamics in shrubland ecosystems, edited by: Hild, A. L., Shaw, N. L., Meyer, S., Booth, D. T., and McArthur, E. D., USDA Forest Service Proceedings RMRS-P-31, Ogden UT:US, 2004.

Flanagan, D. C. and Nearing, M. A. (Eds.): WEPP: USDA-Water Erosion Prediction Project, NSERL Rep. 10, National Soil Erosion Lab., U.S. Dep. of Agric., Laffayette, Indiana, 1995. 
Fox, D. M., Bryan, R. B., and Price, A. G.: The influence of slope angle on infiltration rate and surface seal characteristics for interrill conditions, Geoderma, 80, 181-194, 1997.

Fox, D. M., Le Bissonnais, Y., and Bruand, A.: The effect of ponding depth on infiltration in a crusted surface depression, Catena, 32(2), 87-100, 1998.

Gao, Q. and Reynolds, J. F.: Historical shrub-grass transitions in the northern Chihuahuan Desert: modeling the effects of shifting rainfall seasonality and event size over a landscape gradient, Global Change Biology, 9, 1-19, 2003.

Gilad, E., von Hardenberg, J., Provenzale, A., Schachak, M., and Meron, E.: Ecosystem Engineers: From Pattern Formation to Habitat Creation, Phys. Rev. Lett., 93(9), 098105, doi:10.1103/PhysRevLett.93.098105, 2004.

Henderson, F. M. and Wooding, R. A.: Overland flow and groundwater flow from a steady rainfall of finite duration, J. Geophys. Res., 69, 1531-1540, 1964.

HilleRisLambers, R., Rietkerk, M., van den Bosch, F., Prins, H. H. $\mathrm{T}$., and de Kroon, H.: Vegetation pattern formation in semi-arid grazing systems, Ecology, 82, 50-61, 2001.

Imeson, A. C. and Prinsen, H. A. M.: Vegetation patterns as biological indicators for identifying runoff and sediment source and sink areas for semi-arid landscapes in Spain, Agriculture, Ecosyst. Environ., 104, 333-342, 2004.

Istanbulluoglu, E. and Bras, R. L.: Vegetation-modulated landscape evolution: Effects of vegetation on landscape processes, drainage density, and topography, J. Geophys. Res., 110, F02012, doi:10.1029/2004JF000249, 2005.

Julien, P. Y., Saghafian, B., and Ogden, F. L.: Raster-based hydrologic modeling of spatially varied surface runoff, Water Resour. Bull., 31(3), 523-536, 1995.

Klausmeier, C. A.: Regular and irregular patterns in semiarid vegetation, Science, 284, 1826-1828, 1999.

Lavee, H., Imeson, A. C., and Sarah, P.: The impact of climate change on geomorphology and desertification along a Mediterranean-arid transect, Land Degradation and Development, 9, 407-422, 1998.

Lefever, R. and Lejeune, O.: On the origin of tiger bush, B. Math. Biol., 59, 263-294, 1997.

Ludwig, J. A., Wilcox, B. P., Breshears, D. D., Tongway, D. J., and Imeson, A. C.: Vegetation patches and runoff-erosion as interacting ecohydrological processes in semiarid landscapes, Ecology, 86(2), 288-297, 2005.

Ludwig, J. A., Tongway, D. J., and Marsden, S. G.: Stripes, strands or stipples: modelling the influence of three landscape banding patterns on resource capture and productivity in semi-arid woodlands, Australia, Catena, 37, 257-273, 1999.

Ludwig, J. A., Tongway, D. J., Bastin, G., and James, C.: Monitoring ecological indicators of rangeland functional integrity and their relation to biodiversity at local to regional scales, Austral Ecology, 29, 108-120, 2004.

Mitas, L. and Mitasova, H.: Distributed soil erosion simulation for effective erosion prevention, Water Resour. Res., 34(3), 505516, 1998.

Mabbutt, J. A. and Fanning, P. C.: Vegetation banding in arid Western Australia, J. Arid Environ., 12, 41-59, 1987.

Noy-Meir, I.: Desert ecosystems: environment and producers, Ann. Rev. Ecol. Systematics, 4, 25-51, 1973.

Noy-Meir, I.: Spatial effects in modelling of arid ecosystems, in:
Arid Land Ecosystems, edited by: Goodall, D. W. and Perry, R. A., pp 411-433, Cambridge University Press, 1981.

Porporato, A., Laio, F., Ridolfi, L., Caylor, K. K., and RodriguezIturbe, I.: Soil moisture and plant stress dynamics along the Kalahari precipitation gradient, J. Geophys. Res., 108(D3), 4127, doi:10.1029/2002JD002448, 2003.

Puigdefabregas, J. and Sanchez, G.: Geomorphological implications of vegetation patchiness in semi-arid slopes, in: Advances in Hillslope Processes, 2: 1027-1060, edited by: Anderson, M. and Brooks, S., John Wiley, 1996.

Puigdefábregas, J., Sole, A., Gutierrez, L., del Barrio. G., and Boer, M.: Scales and processes of water and sediment redistribution in drylands: results from the Rambla Honda field site in Southeast Spain, Earth-Sci. Rev., 48, 39-70, 1999.

Saco, P. M. and Willgoose G. R.: Modeling Complex Interactions between Ecology, Hydrology and Soil Erosion Patterns in Arid regions, EOS Trans. AGU, 87(52) Fall Meet. Suppl., Abstract H11G-02, 2006.

Sparrow, A. D., Friedel, M. F., and Stafford Smith, D. M.: A landscape-scale model of shrub and herbage dynamics in Central Australia, validated by satellite data, Ecological Modelling, 97, 197-216, 1997.

Slatyer, R. O.: Methodology of a water balance study conducted on a desert woodland Acacia aneura community, Arid Zone Res. 16, 15-26, 1961.

Rietkerk, M., Boerlijst, M. C., Van Langevelde, F., HilleRisLambers, R., van de Koppel, J., Kumar, L., Prins, H. H. T., and de Rooam, A. M.: Self-organization of vegetation in arid ecosystems, American Naturalist, 160, 524-530, 2002.

Thiery, J. M., D'Herbes, J. M., and Valentin, C.: A model simulating the genesis of banded vegetation patterns in Niger, J. Ecol., 83, 497-507, 1995.

Tongway, D. J. and Ludwig, J. A.: Vegetation and soil patterning in semi-arid mulga lands of Eastern Australia, Aust. J. Ecol., 15, 23-34, 1990.

Tongway, D. J. and Ludwig, J. A.: The conservation of water and nutrients within landscapes, in: Landscape Ecology, Function and Management: Principles from Australia's Rangelands, Chap. 2, edited by: Ludwig, J., Tongway, D., Freudenberger, D., Noble, J., and Hodgkinson, K., CSIRO Publishing, Melbourne, 13-22, 1997.

Tongway, D. J. and Ludwig, J. A.: Theories on the origins, maintenance, dynamics, and functioning of banded landscapes, in Banded vegetation patterning in arid and semiarid environments: ecological processes and consequences for management, Ecological studies 149, Springer-Verlag, New York, USA, 20-31, 2001.

Tongway, D. J., Ludwig, J. A., and Whitford, W. G.: Mulga log mounds: fertile patches in the semi-arid woodlands of eastern Australia, Aust. J. Ecol., 14, 263-268, 1989.

Valentin, C. and d'Herbes, J. M.: Niger tiger bush as a natural water harvesting system, Catena, 37, 231-256, 1999.

Valentin, C., d'Herbes, J. M., and Poesen, J.: Soil and water components of banded vegetation patterns, Catena, 37, 1-24, 1999.

Vieux, B. E.: Geographic information systems and non-point source water quality and quantity modelling, Hydrol. Processes, 5(1), 101-113, 1991.

Wakelin-King, G. A.: Banded mosaic ("tiger-bush") and sheetflow plains: a regional mapping approach, Aust. J. Earth Sci., 46, 53$58,1999$. 
Walker, B. H., Ludwig, D., Holling, C. S., and Peterman, R. M.: Stability of semi-arid savanna grazing systems, J. Ecol., 69, 473498, 1981.

Wilcox, B. P., Breshears, D. D., and Allen, C. D.: Ecohydrology of a resource-conserving semiarid woodland: effects of scale and disturbance, Ecological Monographs, 73(2), 223-239, 2003.

Willgoose, G. R.: User Manual for EAMS SIBERIA 8.30, www. telluricresearch.com/siberia_8.30_manual.pdf, 2004.
Willgoose, G. R., Bras, R. L., and Rodriguez-Iturbe I.: A physically based coupled network growth and hillslope evolution model: 1 Theory, Water Resour. Res., 27(7), 1671-1684, 1991.

Woolhiser, D. A. and Liggett, J. A.: One-dimensional flow over a plane: The rising hydrograph, Water Resour. Res., 3(3), 753771, 1967.

Zhang, H.: Organic matter incorporation affects mechanical properties of soil aggregates, Soil Tillage Res., 31, 263-275, 1994. 